\title{
PENGEMBANGAN USAHA INDUSTRI KREATIF PANGAN LOKAL KHAS PANJALU KABUPATEN CIAMIS
}

\author{
Reni Marlina \\ reni.marlina@ekuitas.ac.id \\ Yudi Wahyudin \\ yudisuwandi@gmail.com \\ Lina Said \\ linasaid312@yahoo.com
}

SEKOLAH TINGGI ILMU EKONOMI EKUITAS

\begin{abstract}
ABSTRAK
Upaya dalam mengembangkan dan meningkatkan usaha para UKM pangan lokal khas Kec. Panjalu Kabupaten Ciamis, Jawa Baratyang dikenal dengan tempat wisata ziarah Situ Lengkong terus dilakukan. Sebagai tujuan wisata, terdapat makanan khas lokal yang cukup dikenal, namun pemasarannya masih belum cukup luas.Dalam menjalankan usahanya, penghasil makanan khas ini masih menjalankan usaha secara tradisional, yaitu belum mengelola usaha sesuai dengan manajemen usaha secara baik dan benar. Sistem pemasaran masih dari mulut ke mulut belum menggunakan sistem pemasaran berbasis teknologi, aspek keuangan kurang baik karena tidak ada pembukuan secara tertulis. Adapun tujuan pengabdian ini adalah agar para UKM dapat mengelola usahanya dengan baik. Pelaksanaan pengabdian pada masyarakat ini diberikan dalam bentuk pelatihan kepada para UKM. Setelah pelatihan ini, pelaku usaha ini diharapkan semakin baik dalam manajemen usaha dan pemasarannya.
\end{abstract}

Kata Kunci: Manajemen Usaha; Pembukuan

\section{LATAR BELAKANG}

Panjalu adalah salah satu kecamatan di Wilayah Utara Kabupaten Ciamis Jawa Barat. Dalam kaitan dengan sejarah berdirinya Kabupaten Ciamis, peran daerah Panjalu sangatlah strategis, mengingat di daerah ini terdapat beberapa penemuan yang menunjukkan asal muasal berdirinya sebuah kerajaan kuno. Di Panjalu terdapat Situ Lengkong dan makam-makam para pendahulu Kerajaan kuno tersebut. Konon, di kawasan Situ Lengkong itulah dahulunya menjadi pusat pemerintahan Kerajaan Soko Galuh Panjalu. Dengan adanya penemuan- penemuan sejarah itu, maka Panjalu berkembang sebagai kota daerah wisata, baik wisata alam, wisata budaya maupun sebagai wisata ziarah.

Pentingnya daerah Panjalu sebagai cikal bakal kerajaan Sunda Kawali, maka Pemerintah Propinsi Jawa Barat, pada tanggal 17 Maret tahun 2004 mengukuhkan Panjalu sebagai desa wisata. Panjalu bukan hanya sebagai kampung adat yang memiliki potensi wisata alam, wisata ziarah dan wisata budaya tetapi juga memiliki wisata kuliner yang sangat mendukung.

Panjalu banyak memiliki makanan khas yang unik, menarik dan enak rasanya. 
Makanan khas Panjalu tersebar di beberapa daerah, seperti Kalua Jeruk pusatnya di Desa Kertamandala dan Mandalare, Jawadah Takir (sejenis Wajit) di Garahang, GorengMujaerdanUdang di Cimendong, Opak, Kolontong, Saroja dan Raginang di Desa Maparah, Mie Golosor di Desa Sanding taman dan lainlain. Makanan khas Panjalu ini memiliki rasa yang gurih, unik dan tahan lama. Jawadah takir, kalua jeruk dan saroja menjadi makanan yang khas dari Panjalu. Jawadah Takir, rasanya manis sejenis wajit tetapi kemasannya terbuka menggunakan tekor yang terbuat dari daun pisang yang telah dikeringkan. Kalua jeruk, hasil olahan kulit jeruk bali, rasanya manis. Sementara itu, Saroja bentuknya yang menyerupai kembang seroja membuat makanan ringan ini tampak begitu unik. Jawadah takir, kalua jeruk, comring dan saroja disajikan sebagai salah satu makanan ringan yang dapat disantap saat bersantai, dan seringkali menjadi salah satu buah tangan khas Panjalu.

Daerah penghasil makanan khas tersebut berada di Kecamatan Panjalu dan sekitarnya. Para perajin Jawadah takir berada di Desa Garahang Kec. Panjalu, Kalua Jeruk di Mandalare Kec. Panjalu dan Saroja dihasilkan desa Ciawi luar dan desa Lumbung di Kecamatan Lumbung, desa Girilaya di kecamatan Panawangan dan desa Mekarwangi di kecamatan Sukamantri. Makanan khas tersebut dalam proses pembuatannya masih secara tradisional belum tersentuh oleh cara modern, menggunakan bahan-bahan alami tidak ada campuran bahan pengawet atau zat kimia. Makanan ini bertahan kurang lebih 1 (satu) bulan atau lebih tergantung tempat penyimpanan dan suhu di ruangannya. Kemasan makanan tersebut masih sangat sederhana.

Dalam menjalankan usahanya, penghasil makanan khas ini masih menjalankan usaha secara tradisional, yaitu belum mengelola usaha sesuai dengan manajemen usaha secara baik dan benar. Sistem pemasaran masih dari mulut ke mulut belum menggunakan sistem pemasaran berbasis teknologi, aspek keuangan kurang baik karena tidak ada pembukuan secara tertulis.

Adapun Permasalahan yang dihadapi oleh UKM makanan khas dalam mengembangkan usahanya di Kec. Panjalu Kabupaten Ciamis Jawa Barat sebagai calon Mitra adalah :

1. Pemasaran makanan khas yang masih sangat terbatas dan masih menggunakan metode pemasaran dari mulut ke mulut atau tradisional.

2. Belum memiliki manajemen usaha.

3. Belum memiliki pembukuan secara tertulis.

\section{METODOLOGI PELAKSANAAN}

Metode pelaksanaan pengabdian berupa pelatihan kepada mitra di Kecamatan Panjalu. Pelatihan yang dilaksanakan terkait manajemen usaha dan manajemen keuangan dan pembukuan sederhana. Pemberian pelatihan dilanjutkan dengan Tanya jawab.

Metode yang digunakan dalam kegiatan pengabdian ini adalah:

1. Pembukaan

2. Pelatihan Manajemen Usaha terutama yang berkaitan dengan pemasaran produk.

3. Pelatihan Manajemen Keuangan Usaha Kecil

4. Pelatihan konsep-konsep dasar pembukuan sederhana.

5. Penutup.

Kelompok sasaran dari kegiatan pengabdian ini adalah para UKM makanan khas di Kec. Panjalu. Peran serta mitra dan anggota kelompok dalam program ini sangat mendukung terhadap keberhasilan program. Bapak Rahmat sebagai petugas di Bale Desa Panjalu mengumpulkan para UKM penghasil jawadah takir, comring, kalua jeruk dan makanan kecil khas Panjalu lainnya. 
Pengabdian pada masyarakat ini diberikan dalam bentuk pelatihan, yaitu dengan penyampaian materi dalam bentuk modul Manajemen usaha, manajemen keuangan dan pembukuan sederhana (materi terlampir).

\section{HASIL DAN LUARAN}

Pengembangan usaha industri kreatif pangan lokal khas Panjalu Kabupaten Ciamis adalah dalam bentuk pelatihan yang diberikan kepada usaha kecil pangan lokal di desa Panjalu yaitu usaha Jawadah Takir di desa Garahang Panjalu Ciamis, Comring, dan lain-lain. Pelatihan diberikan kepada usaha kecil pembuat Jawadah Takir, yaitu yang terdiri dari lima usaha kecil. Bapak Endri Sobandi, Ibu Ipin dan Bapak Ma'mun, Ibu Edah dan usaha Comring Ibu Dedeh. Pelatihan yang diberikan berupa pelatihan, yaitu pelatihan marketing online, manajemen usaha, manajemen keuangan usaha kecil dan pembukuan sederhana. Materi pelatihan bersumber dari buku Pembukuan Sederhana Usaha Dagang dan Jasa (Ayu dan Doni, 2013), Cara Mudah Membuat Pembukuan Sederhana (Hery, 2015), E-Marketing SMART Technique for Entrepreneur (Kanaidi, 2013), EMarketing (Judy, 2013).

Para pelaku usaha diberikan pelatihan marketing online, manajemen usaha, manajemen keuangan usaha kecil dan pembukuan sederhana. Pelaku usaha sangat antusias terhadap materi pelatihan yang diberikan. Salah satu pelaku usaha JawadahTakir, yaitu Ibu Edah selama ini lebih banyak membuat produk hanya berdasarkan pesanan sehingga tidak menentu jadwal produksinya dan dalam menentukan harga jual hanya berdasarkan perkiraan dari harga beli bahan baku dan belum mempunyai catatan keuangan. Bahan baku yang digunakan adalah gula putih, kelapa dan tepung dan diberi alas dari daun pisang yang diberi nama"tekor". Jawadah Takir dijual dalam dua ukuran, yaitu ukuran kecil dan besar. Untuk ukuran kecil dijual dengan harga Rp 4.000,00 (isi 20 buah) dan ukuran besar Rp 20.000,00 (isi 55 buah) dengan daya tahan setelah produksi selama 1 bulan.

Luaran dari kegiatan Pengabdian Masyarakat ini adalah berupa Modul pelatihan manajemen usaha, manajemen keuangan usaha kecil dan pembukuan sederhana.

Kegiatan pengabdian pada masyarakat dalam bentuk pelatihan di Kec. Panjalu adalah sebagai bentuk perwujudan kepedulian STIE Ekuitas untuk berpartisipasi secara aktif membantu dalam mengembangkan usahanya di Kec. Panjalu Kabupaten Ciamis Jawa Barat.

Kegiatan pengabdian pada masyarakat dengan kelompok sasaran dalam hal ini adalah UKM makanan khas dalam mengembangkan usahanya di Kec. Panjalu Kabupaten Ciamis Jawa Barat.

Manfaat kegiatan pengabdian pada masyarakat untuk pelaksana kegiatan adalah sebagai bentuk Pengabdian sebagai Dosen dan Pelaksanaan Tridharma Perguruan Tinggi.

\section{KESIMPULAN}

Pengabdian kepada masyarakat yang dilaksanakan kepada UKMmakanan khas dalam mengembangkan usahanya di Kec. Panjalu Kabupaten Ciamis Jawa Barat. Materi pelatihan berupa pelatihan marketing online, manajemen usaha, manajemen keuangan usaha kecil dan pembukuan sederhana. Dengan adanya pelatihan ini, diharapkan dapat membantu UKM pangan khas lokal dalam mengembangkan usahanya di Kec. Panjalu Kabupaten Ciamis Jawa Barat.

\section{DAFTAR PUSTAKA}
Ayu, A.,dan Doni, S. (2013). Pembukuan Sederhana Usaha Dagang dan Jasa. Jakarta: Laskar Aksara.


Hery. (2015). Cara Mudah Membuat Pembukuan Sederhana. Jakarta: Grasindo.

Kanaidi. (2013). Workshop: e Marketing SMART
Technique
Entrepreneurs.Bandung: Politeknik Pos Indonesia.

Judy, S. dan Raymond, F. (2013). E Marketing. Routlegde. 